\title{
Spatial and temporal assessment of radiofrequency electromagnetic fields emitted by smart meters and smart meter banks in urban environments
}

Authors: Sam Aertsa,*, Matthias Van den Bossche ${ }^{a}$, Ximena Vergara ${ }^{\mathrm{b}}$, Simon Odie $^{\mathrm{c}}$, Leen Verloock ${ }^{\mathrm{a}}$, Luc Martens ${ }^{\mathrm{a}}$, and Wout Joseph ${ }^{\mathrm{a}}$

${ }^{a}$ Department of Information Technology, Ghent University / IMEC, Technologiepark-Zwijnaarde 126, Ghent, Belgium

b Electric Power Research Institute (EPRI), 3420 Hillview Avenue, Palo Alto, California 94304, USA

${ }^{\mathrm{c}}$ Consolidated Edison Company of New York, Inc. (Con Edison), 4 Irving Place, 22 ${ }^{\text {nd }}$ floor, , New York, New York 10003, USA

* Corresponding author: Sam.Aerts@UGent.be 


\begin{abstract}
This paper describes radiofrequency (RF) electromagnetic field (EMF) measurements in the vicinity of single and banks of advanced metering infrastructure (AMI) smart meters. The measurements were performed in a meter testing and distribution facility as well as in-situ at five urban locations. The measurements consisted of gauging the RF environment at the place of assessment, evaluating the worstcase electric-field levels at various positions around the assessed AMI meter configuration (spatial assessment), which ranged from a single meter to a bank of 81 meters, and calculating the duty cycle of the system, i.e. the fraction of time that the AMI meters were actually transmitting (12-hour temporal assessment). Both in-situ and in the meter facility, the maximum field levels at $0.3 \mathrm{~m}$ from the meter configurations were $10-13 \mathrm{~V} / \mathrm{m}$ for a single meter and $18-38 \mathrm{~V} / \mathrm{m}$ for meter banks with 20 to 81 meters. Furthermore, 6-minute average duty cycles of $0.01 \%$ (one meter) up to $13 \%$ (81-meter bank) were observed. Next, two general statistical models (one for a single meter and one for a meter bank) were constructed to predict the electric-field strength as a function of distance to any configuration of the assessed AMI meters. For all scenarios, the measured exposure levels (at a minimum distance of $0.3 \mathrm{~m}$ ) were well below the maximum permissible exposure limits issued by the International Commission on Non-Ionizing Radiation Protection (ICNIRP), the U.S. Federal Communications Commission (FCC), and the Institute of Electrical and Electronics Engineers (IEEE). Indeed, the worst-case time-average exposure level at a distance of $0.3 \mathrm{~m}$ from an AMI installation was $5.39 \%$ of the FCC/IEEE and $9.43 \%$ of the ICNIRP reference levels.
\end{abstract}

Keywords: Advanced Metering Infrastructure (AMI); Radiofrequency Electromagnetic Fields (RFEMF); Exposure Assessment; Smart Meter; Electric Utility Metering 


\section{Acknowledgment}

This work was supported by the Electric Power Research Institute (Contract \#0010007196). X. Vergara is an employee of the Electric Power Research Institute. S. Aerts is a Post-Doctoral Fellow of the FWO-V (Research Foundation-Flanders). The authors would like to thank B. Olsen (EPRI) for his valuable comments, and W. Slade, S. Go, C. Feldman, W. Azzoli, W. Fairechio, et al. (Consolidated Edison Company of New York, Inc. (Con Edison) for their cooperation throughout this study. The measurements described in this study were performed at a Con Edison meter shop and in-situ at various customer locations in the Con Edison service territory. 


\section{Introduction}

The introduction of advanced metering infrastructure (AMI) technologies into electric company service territories in the United States (US) has spurred public concern about exposure to the radiofrequency (RF) electromagnetic fields (EMF) of AMI, also known as "smart meters." In collaboration with electric companies, the US Electric Power Research Institute (EPRI, Palo Alto, CA, USA) performed characterizations of RF-EMF from smart meters in 2011 to respond to queries from the general public about RF-EMF exposures and upcoming smart meter rollouts (Foster and Tell, 2013; Tell et al., 2012; 2013). In the last few years, smart meter exposure assessments were also carried out in Australia (Girnara et al., 2011), Belgium (Aerts et al., 2019), Great Britain (Peyman et al., 2017; Calderon et al., 2019), and Spain (de Miguel-Bilbao et al., 2017).

In general, a smart meter can represent a node in three types of networks: a home area network (HAN), a neighborhood area network (NAN), and a wide area network (WAN). In a WAN, devices transmit data directly to the utility. WAN devices are also called collectors, access points, or gateways. A NAN consists of multiple devices (spread over a number of residences), that may be interconnected in a mesh network, of which the data are sent to a WAN gateway. And finally, in a HAN, several devices in the same residence (e.g. in-home displays, communications hubs, gas meters, electricity meters, and water meters) are interconnected (wired or wirelessly) while one of them transmits the combined meter readings to a collector (which makes it part of a NAN) or directly to the utility (which makes it part of a WAN). Depending on the type of network, different wireless technologies for data transmission can be used. In previous studies, this included ZigBee at 2.4 GHz in a HAN (Peyman et al., 2017; Calderon et al., 2019), Mesh Radio in the Industrial, Scientific and Medical (ISM) 915 MHz band (902-928 MHz) in a NAN (Girnara et al., 2011; Foster and Tell, 2013; Tell et al., 2012; 2013), Worldwide Interoperability for Microwave Access (WiMAX) at $2.3 \mathrm{GHz}$ in a NAN (Girnara et al., 2011), and cellular technologies such as Long Term Evolution (LTE) (de Miguel-Bilbao et al., 2017) and General Packet Radio Service (GPRS) in a WAN (Aerts et al., 2019).

Despite previous efforts, specific concerns about RF-EMF have been raised by people living in urban environments. These areas have higher population densities and more people living in close proximity to one another than the less urban areas assessed in previous studies. Moreover, actual long-term measurements of AMI transmissions and accurate evaluations of the exposure to multiple-meter configurations (meter banks) in NANs, as often present in these environments, are currently lacking.

This paper describes the RF exposure assessment performed for various configurations of AMI smart meters operating in the ISM $915 \mathrm{MHz}$ band in urban environments in New York City and Westchester County, New York. Through previous work, a protocol was developed for the evaluation of exposure to residential, potentially non-continuous RF sources (Aerts et al., 2019). Besides characterization of the RF environment, this protocol comprises two separate measurements: (a) (worst-case) exposure level 
measurements - to assess the maximum electric field strength at certain positions in relation to the source (i.e. spatial assessment); and (b) duty cycle (DC) measurements - to determine the frequency and duration of the RF transmissions (i.e. temporal assessment). Both measurements are combined to obtain the time-averaged exposure levels, which were then compared to maximum permissible exposure guidelines issued by the International Commission on Non-Ionizing Radiation Protection (ICNIRP, 1998), the US Federal Communications Commission (FCC, 1997), and the Institute of Electrical and Electronics Engineers (IEEE, 2005). It was concluded that for all assessed AMI smart meter scenarios, the measured exposure levels (as close to the meter configuration as $0.3 \mathrm{~m}$ were well below the maximum permissible exposure limits issued by ICNIRP, the FCC, and IEEE.

The measurements described in this paper were carried out in a smart meter testing and distribution facility, to evaluate and streamline the measurement procedure, and in five diverse urban environments. The novel methods presented in this paper include: (i) a general exposure evaluation procedure for smart meters, which includes (ii) assessing both spatial and temporal exposure levels and measuring the realduty cycle, (iii) the in-situ assessment of multiple meter banks, (iv) a statistical exposure-distance model for rapid exposure predictions, and (v) the comparison of the potential exposures to smart meters and meter banks with the exposures to other residential sources of RF-EMF (Aerts et al., 2019). This study further serves to provide much-needed information on potential RF exposures in residential locations in the framework of large-scale AMI rollouts in areas with dense populations.

\section{Materials and methods}

\subsection{Advanced Metering Infrastructure}

The AMI smart meters under test were of the type Aclara I-210+cn (with network interface card NIC511) (www.aclara.com, Aclara Technologies LLC, St. Louis, MO, USA). As part of local mesh networks provided by Silver Spring Networks (https://www.itron.com/na/, San Jose, CA, USA), the assessed Aclara smart meters operated in the US unlicensed Industrial, Scientific and Medical (ISM) $915 \mathrm{MHz}$ band (902-928 MHz). The assessed smart meters used the frequency-hopping spread spectrum (FHSS) transmission method with 83 300-kHz-spaced channels in its "default" configuration. The Aclara I-210+cn has a nominal peak power of $1 \mathrm{~W}(30 \mathrm{dBm})$. It should be noted that this device is similar to the ones assessed by Girnara et al. (2011), Foster and Tell (2013), and Tell et al. (2012, 2013). In a mesh network (NAN), smart meters at customer locations (also called "end-point" meters) transmit (and also relay) electrical usage data to a collection or access point (i.e. a WAN gateway) that communicates wirelessly to the central network of the utility company, usually via a mobile telephone network. The rate at which smart meters transmit data to the network's access point is controlled by the meter read-out transmission interval (TI), typically $15 \mathrm{~min}$ for household customers, not including any intermediate or end-point-to-end-point (relay) communications. 


\subsection{Measurement locations and smart meter (bank) configurations}

The first phase of the measurements took place in a smart-meter testing and distribution facility ("meter shop") and consisted of the assessment of a single AMI meter and two multiple meter configurations (meter banks) comprising 24 and 48 smart meters. The second phase involved in-situ measurements at five locations in diverse urban settings, which featured two single smart meters in semi-detached houses and three different meter bank configurations (20, 48, and 81 meters) in apartment complexes (Table 1). All measurements were performed in New York City and Westchester County, New York in 2018.

Table 1: Characteristics of the five in-situ measurement sites (and the present AMI meter configurations) in New York City and Westchester County, New York.

\begin{tabular}{|c|c|c|c|}
\hline Site & Building type & $\begin{array}{l}\text { Measurement } \\
\text { location }\end{array}$ & AMI meter configuration \& location \\
\hline IS \#1 & Semi-detached house & Basement & Single meter; corner of basement \\
\hline IS \#2 & Detached house & $\begin{array}{l}\text { Exterior - ground } \\
\text { level }\end{array}$ & Single meter; on exterior (garage) wall \\
\hline IS \#3 & $\begin{array}{l}\text { Low-rise apartment } \\
\text { building }\end{array}$ & Basement & $\begin{array}{l}\text { 46-meter bank; } 5 \text { x } 10 \text { meter arrangement, with two empty } \\
\text { meter slots and two automated meter reading (AMR) } \\
\text { devices }\end{array}$ \\
\hline IS \#4 & $\begin{array}{l}\text { High-rise apartment } \\
\text { complex }\end{array}$ & $5^{\text {th }}$ floor hallway & $\begin{array}{l}\text { 20-meter bank; } 5 \text { x } 4 \text { meter arrangement in a cabinet with } \\
\text { metal sliding door, accessible from hallway }\end{array}$ \\
\hline IS \#5 & $\begin{array}{l}\text { Low-rise apartment } \\
\text { building }\end{array}$ & Basement & $\begin{array}{l}\text { Combination of a } 48-(4 \times 12) \text { meter bank and a } 33-(4 \times 9 \text {, } \\
\text { three empty meter slots }) \text { meter bank on opposite sides of } \\
\text { the room }\end{array}$ \\
\hline
\end{tabular}

In the meter shop, two identical configurations were constructed. Each consisted of 24 smart meters built in a 4-foot-by-6-foot grid, with standard meter spacing (center-to-center distance: 10" or $25.4 \mathrm{~cm}$ ), on a hardwood panel mounted on a movable cart (Figure 1). Each meter could be powered on/off via toggle switches. Three setups were considered for the measurements: a single-meter setup (MS \#1), a 24-meter setup (MS \#2), and a 48-meter setup (MS \#3). For the meter shop measurements, the read-out TI of the AMI meters was configured to $5 \mathrm{~min}$ instead of the default $15 \mathrm{~min}$ to speed up the measurements. 


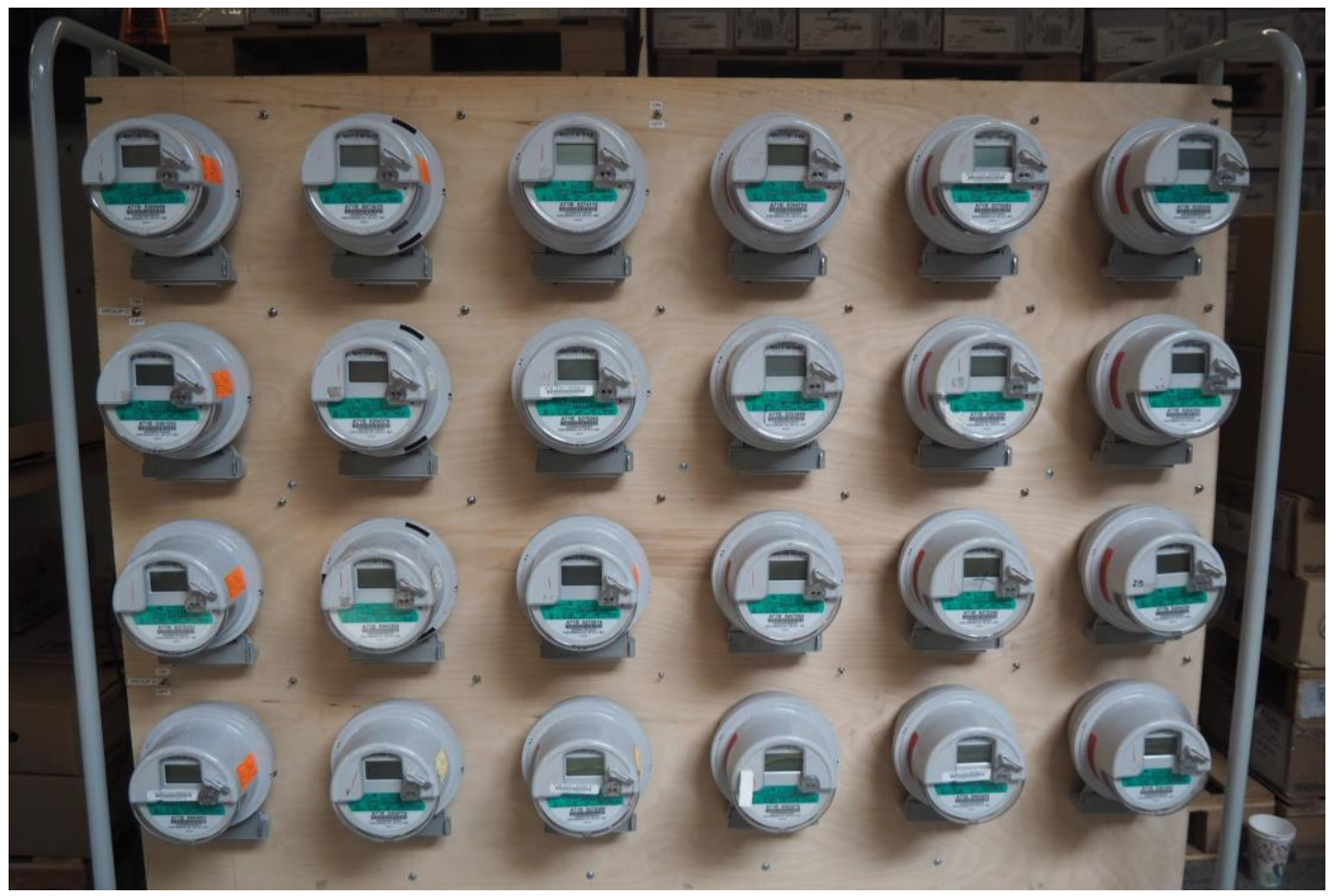

Figure 1: 24 AMI meters (type Aclara I-210+cn, NIC-511) attached to hardwood panel and mounted on a movable cart for easy configuration. Each row, column, or individual meter could be powered on/off.

\subsection{Exposure assessment}

The measurement equipment used in this study consisted of a signal and spectrum analyzer (SA) of type Rohde \& Schwarz (www.rohde-schwarz.com, R\&S, Munich, Germany) FSV30 with a frequency range of $10 \mathrm{~Hz}$ to $30 \mathrm{GHz}$ combined with an isotropic tri-axial antenna (also called a "probe") of type R\&S TS-EMF-B1 (Figure 2). The probe contains electronically switched, orthogonally arranged antenna elements with a frequency range of $30 \mathrm{MHz}$ to $3 \mathrm{GHz}$ and a dynamic measurement range of $1 \mathrm{mV} / \mathrm{m}$ to $100 \mathrm{~V} / \mathrm{m}$ (Aerts et al., 2019). The expanded measurement uncertainty is $\pm 3 \mathrm{~dB}$ for the considered setup (CENELEC 2008; Joseph et al. 2012a). This uncertainty represents the expanded uncertainty evaluated using a confidence interval of $95 \%$. 


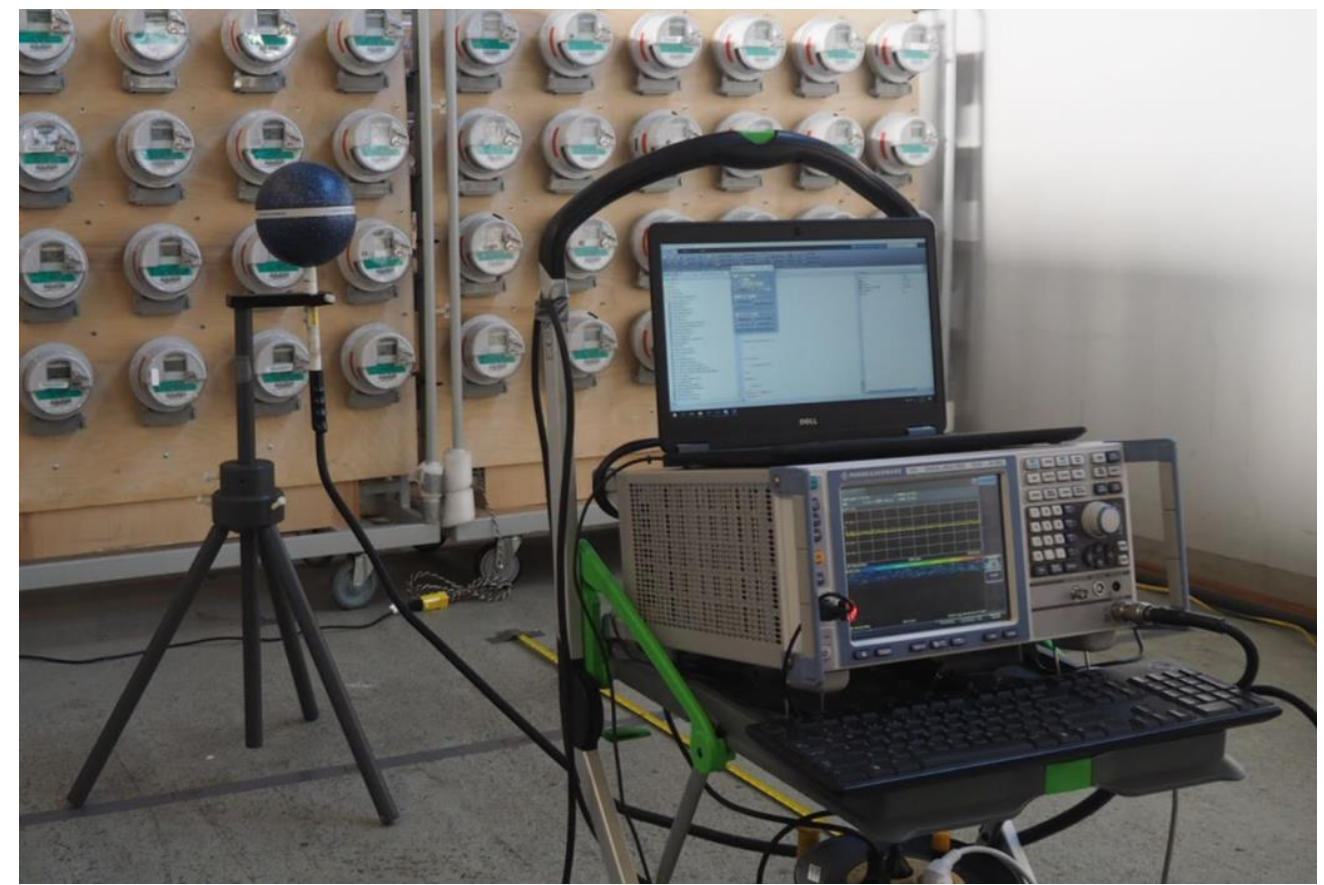

Figure 2: Measurement setup consisting of a Rohde \& Schwarz FSV30 signal and spectrum analyzer (SA), connected to a laptop with Matlab software, combined with an R\&S TS-EMF-B1 isotropic tri-axial antenna.

A flowchart of the procedure to assess the exposure to AMI smart meters is shown in Figure 3.

\section{Step 1) Identification of RF environment}

\section{Step 2) Spatial measurements of worst-case exposure levels}

Step 3) Temporal measurement to obtain duty cycle

Step 4) Calculation of time-averaged exposure levels and comparison to exposure guidelines

Figure 3: Flowchart of the procedure to assess the exposure to AMI smart meters.

First, overview measurements of both a wide frequency range (between $30 \mathrm{MHz}$ and $3 \mathrm{GHz}$ ) and the AMI frequency range $(902-928 \mathrm{MHz})$ were performed at one position near the meter configuration (Figure 3). These measurements identified the RF environment at the measurement location and verified the transmission configuration of the smart meter(s). The SA was used in frequency mode, and the settings included a resolution bandwidth (RBW) of $1 \mathrm{MHz}$ and $300 \mathrm{kHz}$ (to differentiate between the channels used by the AMI transmission technology), respectively, and a sweep time (SWT) for the wideband and in-band measurement of $32 \mathrm{~ms}$ and $2.5 \mathrm{~ms}$, respectively. In both cases, the total measurement time was $45 \mathrm{~s}$ (i.e. $15 \mathrm{~s}$ per $[x, y, z]$ electric-field component). 
Next, worst-case spatial exposure level measurements were performed at various positions around the AMI configuration. For this type of measurement, the zero-span mode of the SA was used, capturing the peak power (using the peak detector) transmitted within the $902-928 \mathrm{MHz}$ band $(\mathrm{CF}=915 \mathrm{MHz}$, RBW = $28 \mathrm{MHz}$ ), every $0.25 \mathrm{~ms}$ (at a SWT of $500 \mathrm{~ms}$ per 2001 sweep points). Each electric-field component was measured consecutively for a minimum time of the typical read-out TI (i.e. $>15 \mathrm{~min}$ for the default household setting and $>5$ min for the meter shop measurements). During post-processing, the maximum field levels per component $\left(E_{i, \max }\right.$, with $\left.i=x, y, z\right)$ were retrieved and the total maximum electric-field strength $\left(E_{\max }\right)$ was calculated as the vector sum. $E_{\max }$ can be considered the exposure level in case of a continuous transmission of the AMI meters under test (i.e. at a DC of 100\%); hence, it is the worst-case, and in practice unrealistic, exposure level.

The (worst-case) electric-field strength $E$ was also modelled as a function of distance $d$ using a generalized log-distance model, based on the free-space path loss model of (Friis, 1946), written as follows,

$$
\log _{10} E=\log _{10} E\left(d_{0}\right)-\mathrm{n} \log _{10} \frac{d}{d_{0}},
$$

with $n$ the model parameter to be fitted (in free space, $n=1$ ) and $E\left(d_{0}\right)$ the electric-field strength at $\mathrm{d}=\mathrm{d}_{0}$ (e.g. $0.3 \mathrm{~m}$ ). Although the electric-field strength is inversely proportional to the distance to the source $(1 / d)$, a generalized model was preferred because $1 / d$ holds only for a single emitter in free space (Friis, 1946).

Third, a 12-hour temporal measurement was performed at one position near the AMI meter configuration under assessment (e.g. at a distance of $0.3 \mathrm{~m}$ ) to obtain the DC and its variability over time. Since only the variation in time of the emitted signals was of interest, a single electric-field component (i.e. the most dominant, based on the spatial measurements) was sufficient to measure. As before, the power in the AMI frequency band was measured in zero-span mode and sampled every $1.87 \mathrm{~ms}$, fast enough to capture the shortest transmissions (i.e. $2 \mathrm{~ms}$ for the specific AMI transmission technology (Tell et al., 2013)). During post-processing, a background power level was determined and the DC was calculated as the ratio of the number of power samples above this threshold to the total number of samples. Depending on the specific compliance assessment, a certain time-averaging window was applied (i.e. $x$ min, with $x=6$ for ICNIRP (1998) and $x=30$ for FCC (1997) and IEEE (2005)).

Lastly, time-averaged exposure levels were obtained using the maximum field levels and the (guideline $X$-specific) time-averaged DC (Verloock et al., 2010), calculated as

$$
E_{\text {avg }, X}=\sqrt{D C_{\mathrm{x}-\min }} E_{\max }[\mathrm{V} / \mathrm{m}] . \quad \text { (Eq. 2) }
$$

This value was then compared to exposure-limiting guidelines by calculating the exposure ratio (ICNIRP, 1998), 


$$
R_{X}=100 \% \times\left(E_{a v g, X} / E_{r e f, X}\right)^{2}[\%],
$$

with $E_{r e f, X}$ the guideline-specific reference level for the electric-field strength at the considered frequency, i.e. $41 \mathrm{~V} / \mathrm{m}$ (ICNIRP, 1998) and 47.6-48.3 V/m (FCC, 1997; IEEE, 2005) for frequencies between $902 \mathrm{MHz}$ and $928 \mathrm{MHz}$. The observed time-averaged exposure levels were well below the ICNIRP, FCC, and IEEE maximum permissible exposure guidelines if $R \leq 1$.

\section{Results and Discussion}

\subsection{Overview measurements}

Figure 4 shows that a multitude of RF signals could be present at a measurement location (in this case, at site IS \#2). Most often they were identified as cellular telecommunications signals (e.g. Global System for Mobile Communications (GSM), Code Division Multiple Access (CDMA), and Long-Term Evolution (LTE)), operating in a variety of frequency bands between roughly $300 \mathrm{MHz}$ and $3500 \mathrm{MHz}$. Other signals observed included Wireless Fidelity (Wi-Fi), television and radio broadcasting, weather radar, and signals in unlicensed ISM bands (US: 902-928 MHz, in which the assessed AMI meters operate, 2400-2848 MHz, and 5725-5875 MHz). Overall, fewer RF signals were detected indoors because of signal attenuation through building walls and windows.

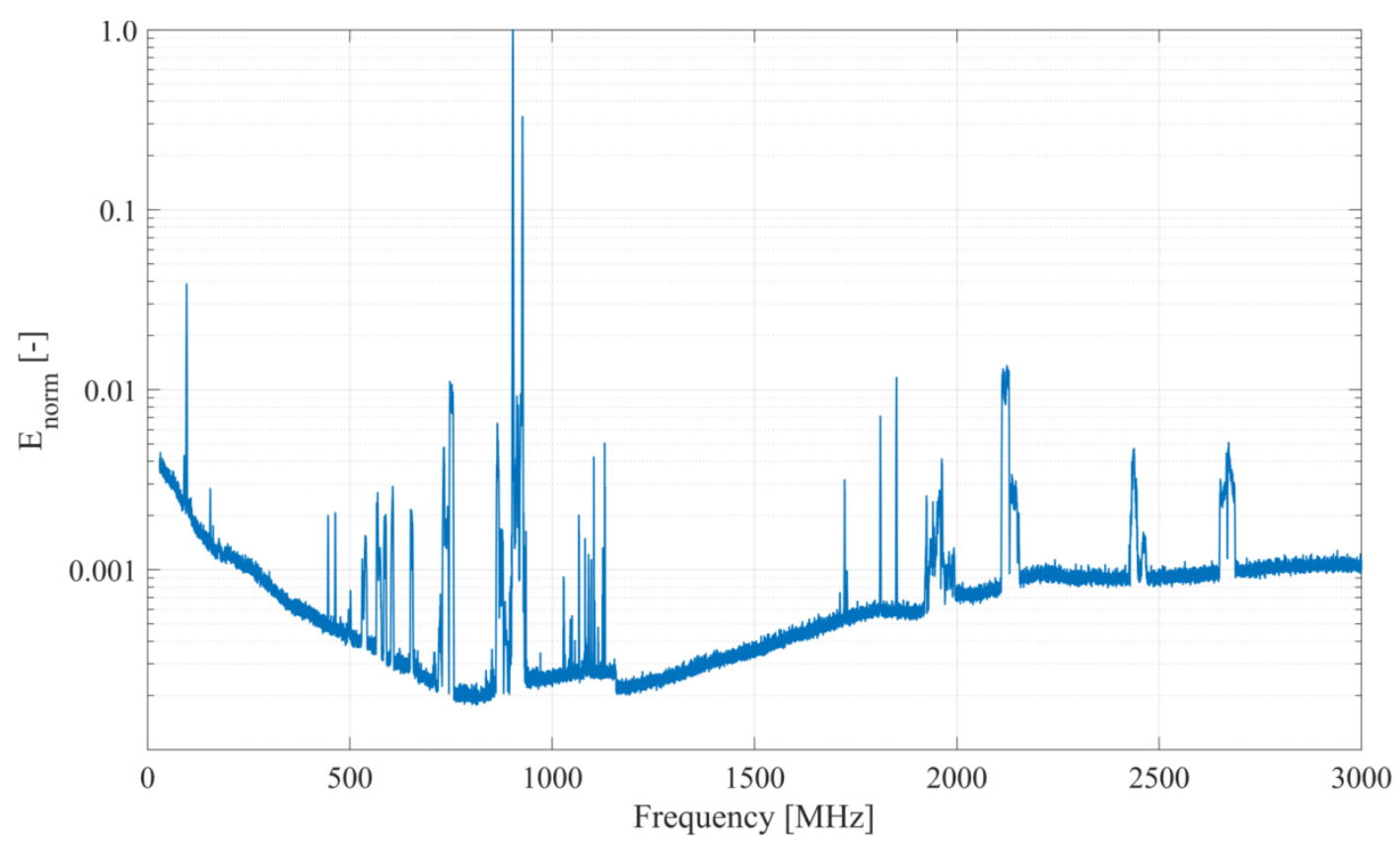

Figure 4: Example of a wide frequency range overview measurement, obtained at in-situ location IS \#2 (E-field strength was normalized to the maximum field level).

Next, an example of an in-band overview measurement (also measured at site IS \#2) is shown in Figure 5. All smart meter configurations assessed in this study used the default 300-kHz channel spacing and 83-channel hopping modulation and operated in the ISM $915 \mathrm{MHz}$ band. Figure 5 also shows only 
a half-occupied AMI frequency band because roughly half of the 83 available frequencies had not been used for transmission within the measurement time frame ( $45 \mathrm{~s})$, as expected from single meters. On the other hand, fully-occupied bands were observed in the case of meter banks (not shown here). Finally, although the ISM $915 \mathrm{MHz}$ band can be used license-free, it is less occupied than, for instance, the unlicensed 2400-2500 MHz band (which includes, for example, nearby Wi-Fi signals and microwave radiation). In fact, at none of the measurement locations were RF signals detected from sources other than the smart meters in the $915 \mathrm{MHz}$ band.

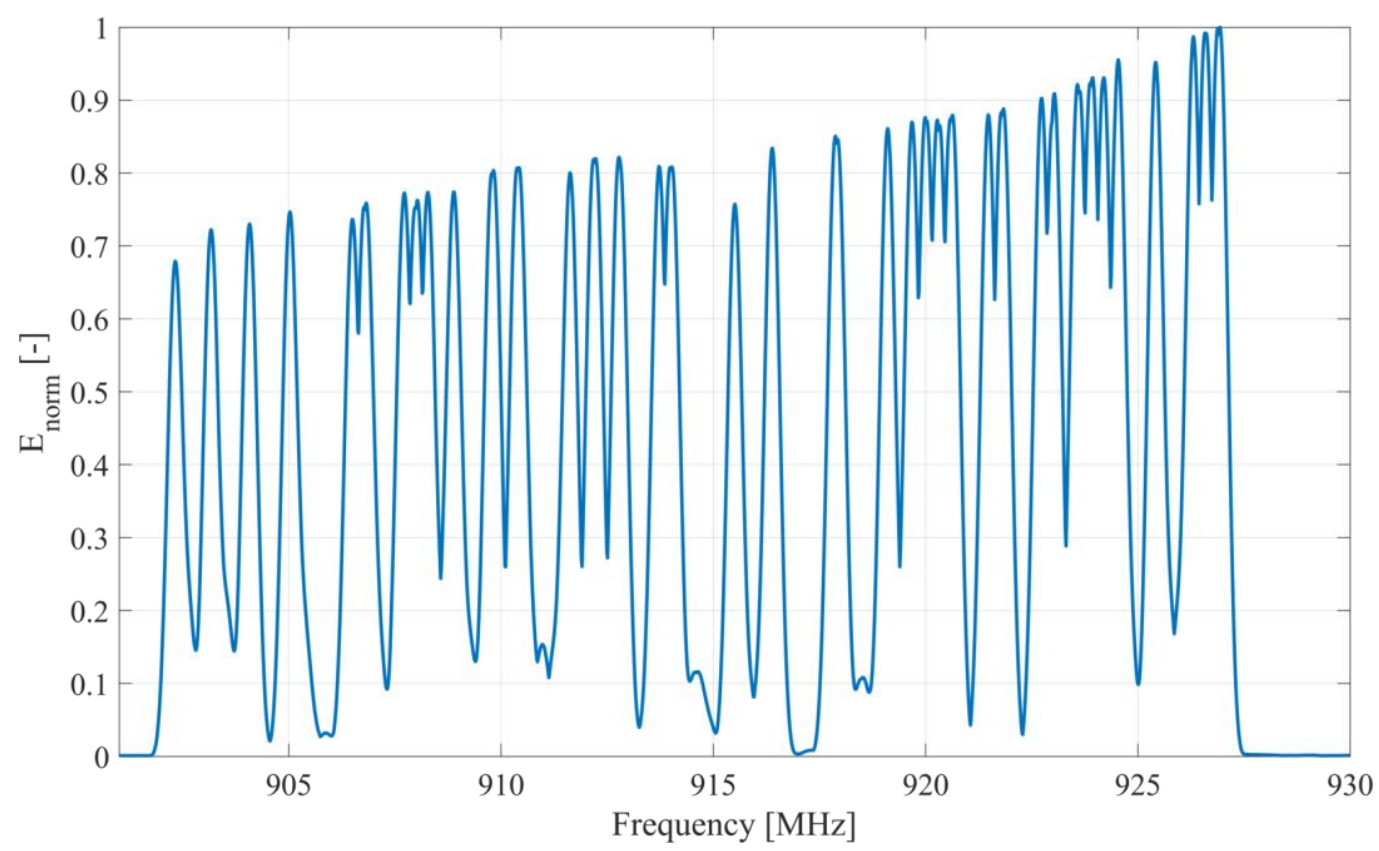

Figure 5: In-band overview measurement from in-situ location IS \#2 (E-field strength was normalized to the maximum field level).

\subsection{Spatial measurements}

To assess the worst-case electric-field values near the smart meter configurations, spatial measurements were performed. When measuring the electric-field strength as a function of distance (Figure 6; the results at $0.3 \mathrm{~m}$ are also listed in Table 2), the probe was positioned along the center axis of the specific meter configuration. As such, the height of the probe differed between measurement locations (from $1.2-1.5 \mathrm{~m})$. Moreover, the measuring distance was calculated from the center of the probe to the center of the front side of the meter (bank).

In the case of a single meter, the worst-case exposure levels as a function of distance were very similar, with $E_{\max }=10.20-12.79 \mathrm{~V} / \mathrm{m}$ at $0.3 \mathrm{~m}$ (Table 2) and a parallel decrease with distance (Figure 6). While the difference in $E_{\max }$ may be caused by deviations in meter output power (e.g. deviations of up to $5 \mathrm{~dB}$ were found by Tell et al. (2013)) or due to measurement uncertainty of the setup (up to $3 \mathrm{~dB}$ ), these values are in line with those reported by Tell et al. (2013), i.e. 10-18 V/m for residential measurements 
and $<15 \mathrm{~V} / \mathrm{m}$ in outdoor laboratory settings at $0.3 \mathrm{~m}$ from the assessed meters (which had a nominal peak power of $1 \mathrm{~W}$ and also operated in the ISM $915 \mathrm{MHz}$ band).

The meter bank measurements at sites MS \#2 (24 smart meters), MS \#3 (48 smart meters), IS \#3 (46 smart meters), and IS \#5 (combination of 48-meter and 33-meter banks) also resulted in comparable $E_{\max }(18.40-26.12 \mathrm{~V} / \mathrm{m}$ at $0.3 \mathrm{~m}$, Table 2), 3-8 dB higher (which corresponds to a two- to seven-fold increase in power density) than the single-meter field levels. Significantly higher fields were measured at site IS \#4 ( $E_{\max }=38.32 \mathrm{~V} / \mathrm{m}$ at $0.3 \mathrm{~m}$, Table 2 ). This was probably because the 20 -meter bank was located inside a metal cabinet and the electromagnetic fields were unable to propagate in any direction other than through the cabinet opening. Moreover, the isolation of the smart meters might have resulted in a more frequent data loss, and thus a higher number of re-transmissions, a higher channel occupation, and finally higher measured electric-field values.

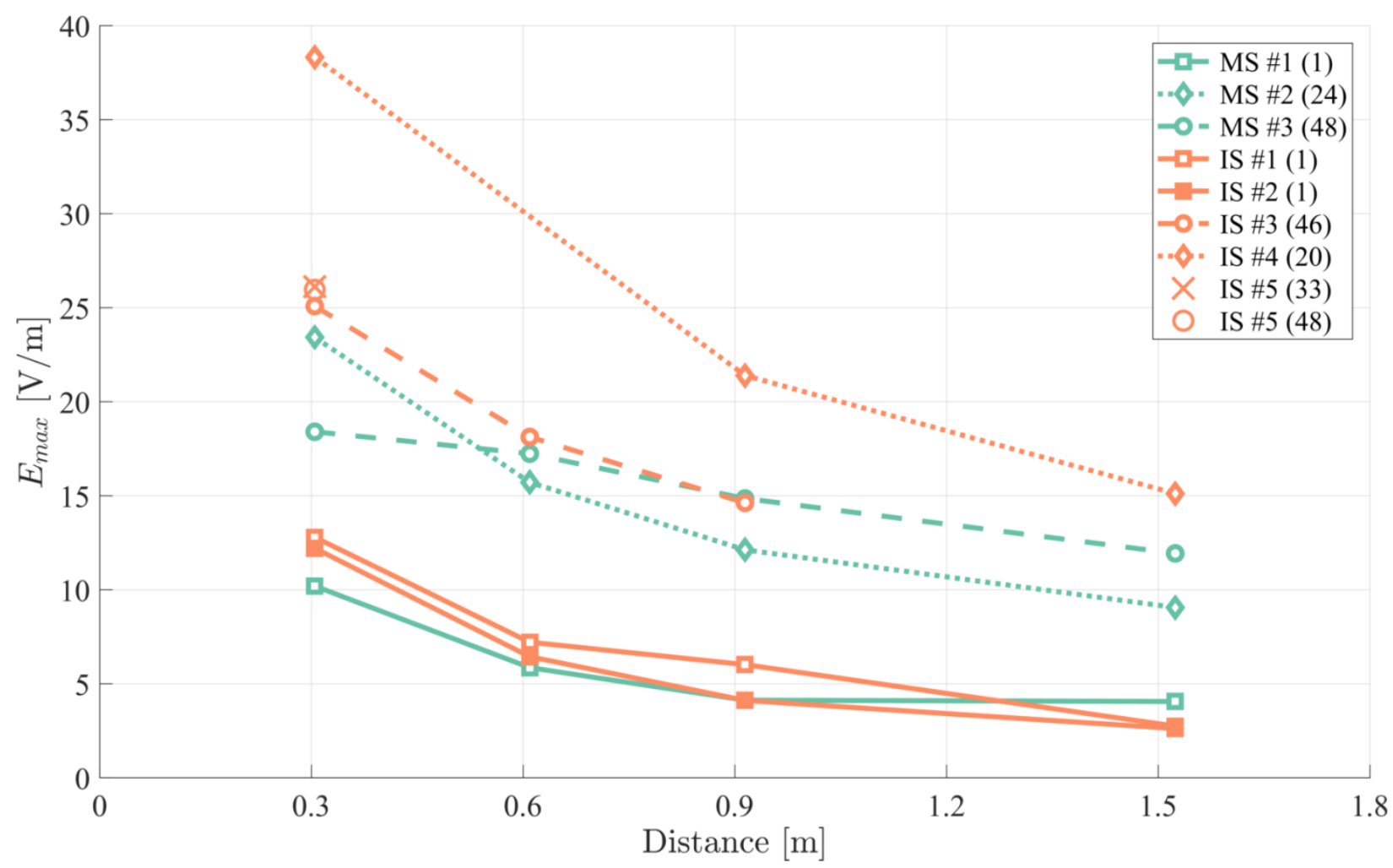

Figure 6: Worst-case electric-field strength $E_{\max }$ (in V/m) as a function of distance (in m) to the assessed AMI meter configurations (MS \#1 to \#3 and IS \#1 to \#5) (in the legend, between brackets is the number of AMI meters of each configuration). 
Table 2: Worst-case field level $\left(E_{\max }\right.$ and $S_{\max }$ at $\left.0.3 \mathrm{~m}\right)$, ranges and averages of obtained duty cycles $\left(\mathrm{DC}_{\mathrm{x}-\mathrm{min}}\right)$, and comparison to the ICNIRP and FCC/IEEE guidelines (via the exposure ratios $R_{\max }$ ) for all assessed situations.

\begin{tabular}{|c|c|c|c|c|c|c|c|c|c|}
\hline \multirow{2}{*}{$\begin{array}{l}\text { Measurement } \\
\text { location }\end{array}$} & \multirow{2}{*}{$\begin{array}{c}\text { Number } \\
\text { of } \\
\text { meters }\end{array}$} & \multirow{2}{*}{$\begin{array}{c}E_{\max } \\
{[\mathrm{V} / \mathrm{m}]}\end{array}$} & \multirow{2}{*}{$\begin{array}{c}S_{\max } \\
{\left[\mathbf{W} / \mathbf{m}^{2}\right]}\end{array}$} & \multicolumn{2}{|c|}{$\begin{array}{c}\text { DC6-min } \\
{[\%]}\end{array}$} & \multicolumn{2}{|c|}{$\begin{array}{c}\text { DC 30-min } \\
{[\%]}\end{array}$} & \multirow{2}{*}{$\begin{array}{c}R_{I C N I R P, \max } \\
{[\%]}\end{array}$} & \multirow{2}{*}{$\begin{array}{c}\boldsymbol{R}_{F C C / I E E E, \max } \\
{[\%]}\end{array}$} \\
\hline & & & & Range & Avg. & Range & Avg. & & \\
\hline MS \#1 & 1 & 10.20 & 0.276 & n.m. & 0.15 & n.m. & 0.15 & 0.01 & 0.01 \\
\hline MS \#2 & 24 & 23.43 & 1.456 & $1.53-5.24$ & 2.51 & $1.94-3.23$ & 2.52 & 1.70 & 0.78 \\
\hline MS \#3 & 48 & 18.40 & 0.898 & $4.25-7.90$ & 5.62 & $4.68-6.67$ & 5.63 & 1.58 & 1.00 \\
\hline IS \#1 & 1 & 12.79 & 0.434 & $0.007-0.07$ & 0.015 & $0.009-0.02$ & 0.015 & 0.007 & 0.001 \\
\hline IS \#2 & 1 & 12.21 & 0.396 & $0.10-0.63$ & 0.20 & $0.15-0.29$ & 0.20 & 0.06 & 0.02 \\
\hline IS \#3 & 46 & 25.08 & 1.669 & $1.10-4.62$ & 2.41 & $1.99-3.13$ & 2.42 & 1.71 & 0.87 \\
\hline IS \#4 & 20 & 38.32 & 3.895 & $3.97-10.89$ & 6.32 & $4.61-8.30$ & 6.34 & 9.43 & 5.39 \\
\hline IS \#5 & 81 & 26.12 & 1.810 & $3.20-12.77$ & 6.42 & $5.25-7.58$ & 6.43 & 5.14 & 2.29 \\
\hline
\end{tabular}

Avg. = average.

The statistical models (one for a single meter, one for a meter bank) of the field strength as a function of distance of Eq. (1) resulted in an excellent fit $\left(R^{2}=0.95-1.00\right)$ and well-replicated electric-field strengths at $0.3 \mathrm{~m}$ (Tables 2 and 3). As the field strengths from the single meters differed little between locations, a model with $n=0.76$ (95\% confidence interval $(\mathrm{CI})=0.70-0.80)$ and $E\left(d_{0}=0.3 \mathrm{~m}\right)=11.72 \mathrm{~V} / \mathrm{m}(95 \% \mathrm{CI}=10.74-12.76 \mathrm{~V} / \mathrm{m})$ (Table 3$)$ can effectively predict the field strength as a function of distance to a single smart meter. Meter banks, on the other hand, may exhibit significantly different meter configurations (compare for example IS \#4 with MS \#3). Hence in order to predict the electric-field strength as a function of distance to a particular meter bank, it is suggested that at least one measurement at a known distance $d_{0}$ be performed and combined with $n=0.55$ (95\% $\mathrm{CI}=0.49-0.62$ ) (the resultant parameter of a model based on combined normalized measurements; last row of Table 3). 
Table 3: Fitted parameters of the model of the (worst-case) electric-field strength $\left(E_{\max }\right)$ as a function of the distance (d) (Eq. (2)) for various meter configurations as well as for combined single meter and meter bank models.

\begin{tabular}{|c|c|c|c|c|}
\hline & Situation & $\begin{array}{c}n \\
{[-]}\end{array}$ & $\begin{array}{c}E\left(d_{0}=0.3 \mathrm{~m}\right) \\
{[\mathrm{V} / \mathrm{m}]}\end{array}$ & $\begin{array}{l}\boldsymbol{R}^{2} \\
{[-]}\end{array}$ \\
\hline \multirow{4}{*}{ 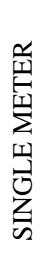 } & MS \#1 & 0.71 & 10.00 & 0.97 \\
\hline & IS \#1 & 0.91 & 13.58 & 0.95 \\
\hline & IS \#2 & 0.97 & 12.27 & 1.00 \\
\hline & Single meter - combined results & 0.76 & 11.72 & 0.97 \\
\hline \multirow{5}{*}{ 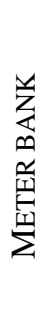 } & MS \#2 (24 meters) & 0.54 & 22.75 & 0.95 \\
\hline & MS \#3 (48 meters) & 0.49 & 22.44 & 0.95 \\
\hline & IS \#3 (46 meters) & 0.49 & 25.18 & 1.00 \\
\hline & IS \#4 (20 meters) & 0.58 & 38.73 & 1.00 \\
\hline & Meter bank - combined results ${ }^{l}$ & 0.55 & -- & 0.97 \\
\hline
\end{tabular}

${ }^{1}$ The meter bank measurements (excluding those from the 48-meter bank in the meter shop) were normalized to the measurement at $0.3 \mathrm{~m}$ and fitted to a model with $E\left(d_{0}\right)=1$ to calculate a combined $n$.

At site IS \#5, an additional measurement was performed near the center of the room between the two panels that can be used to validate the predictive model. The distance to the center of the 33-meter bank was $1.60 \mathrm{~m}$ and to the center of the 48 -meter bank was $1.97 \mathrm{~m}$. The combined predictions, using Eq. (1) with $\mathrm{n}=0.55$ (Table 3$)$ and $E\left(d_{0}=0.3 \mathrm{~m}\right)$ of $26.12 \mathrm{~V} / \mathrm{m}$ (33-meter bank) and $25.96 \mathrm{~V} / \mathrm{m}$ (48-meter bank), resulted in $13.91 \mathrm{~V} / \mathrm{m}$, which is close to the actual measured value of $13.75 \mathrm{~V} / \mathrm{m}$.

In addition, at a few sites, a number of measurements were performed at other positions around the meter configuration. Based on horizontal and/or vertical increment measurements from the center axis, no preferred transmission direction was observed in front of the configuration. (The difference was found to be $+4 \mathrm{~dB}$ to $-5.5 \mathrm{~dB}$, when the increment was less than $0.6 \mathrm{~m}$, but no consistency between locations was found.) To the back, in addition to the $10 \mathrm{~dB}$ attenuation behind the meter due to shielding from the metal 'meter pan' (Tell et al., 2013), a $15 \mathrm{~dB}$ attenuation factor was contributed to a $20-\mathrm{cm}$ cinder block wall. And finally, a 13-17 dB attenuation (i.e. a factor of 20 to 50 lower power density) was observed at IS \#4 with closed metal panel doors, similar to the $16.6 \mathrm{~dB}$ reduction reported by Tell et al. (2013) in similar circumstances.

\subsection{Temporal measurements}

Next, long-term (up to 12 hours) single-axis measurements of the power received in the frequency band 902-928 MHz were performed for all configurations except MS \#1, for which a 16-min, single-axis measurement was performed. The ranges and average values of the 6-min time-averaged duty cycle $\left(\mathrm{DC}_{6-\mathrm{min}}\right)$ for each of the AMI configurations are in Table 2. Figures 6 and 7 show the temporal variation 
in the 6-min and 30-min average DC of two single meters (IS \#1 and IS \#2) and three meter banks (MS \#2, IS \#4, and IS \#5), respectively.

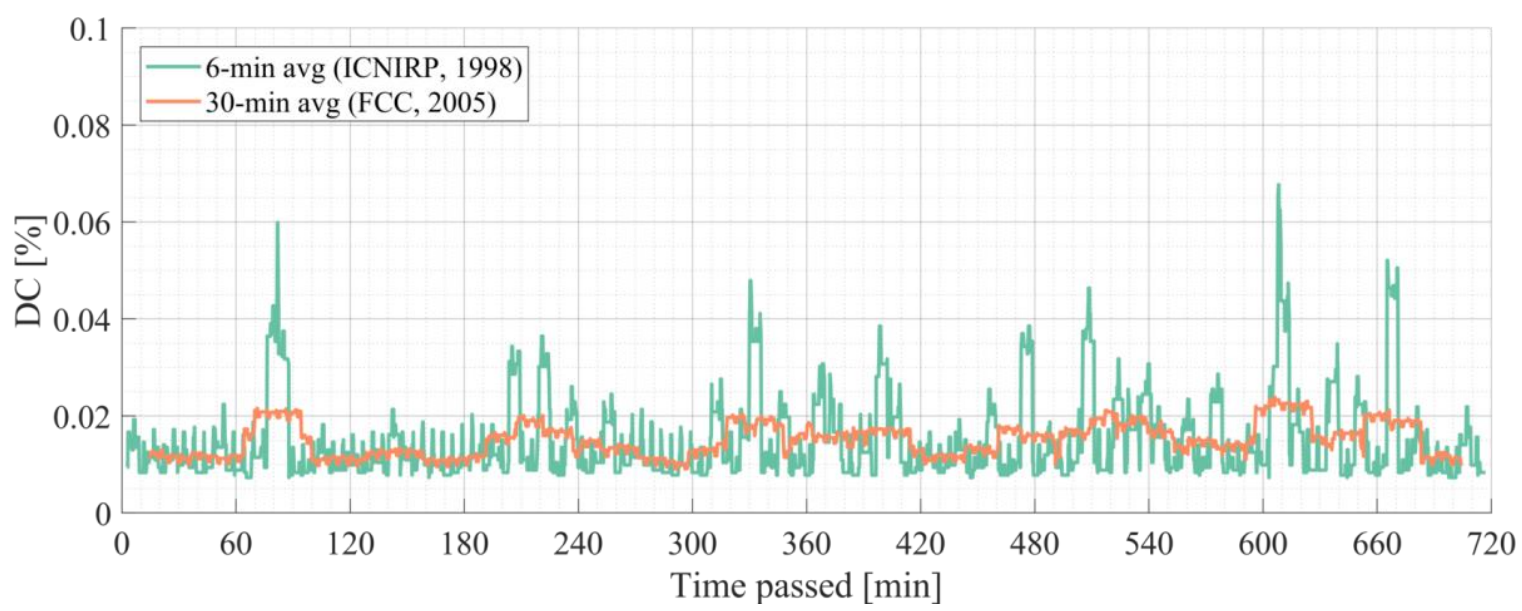

(a) IS \#1

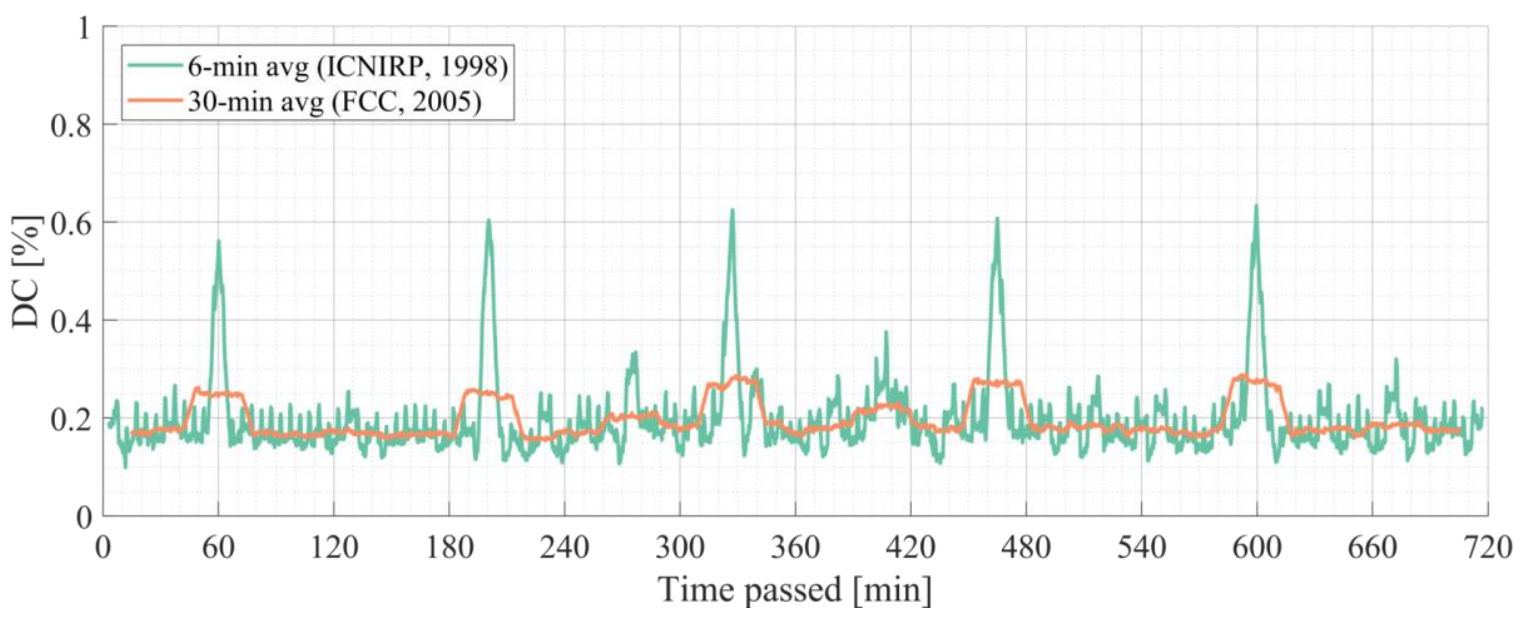

(b) IS \#2

Figure 7: Temporal measurements of single AMI meters at (a) IS \#1 and (b) IS \#2. 


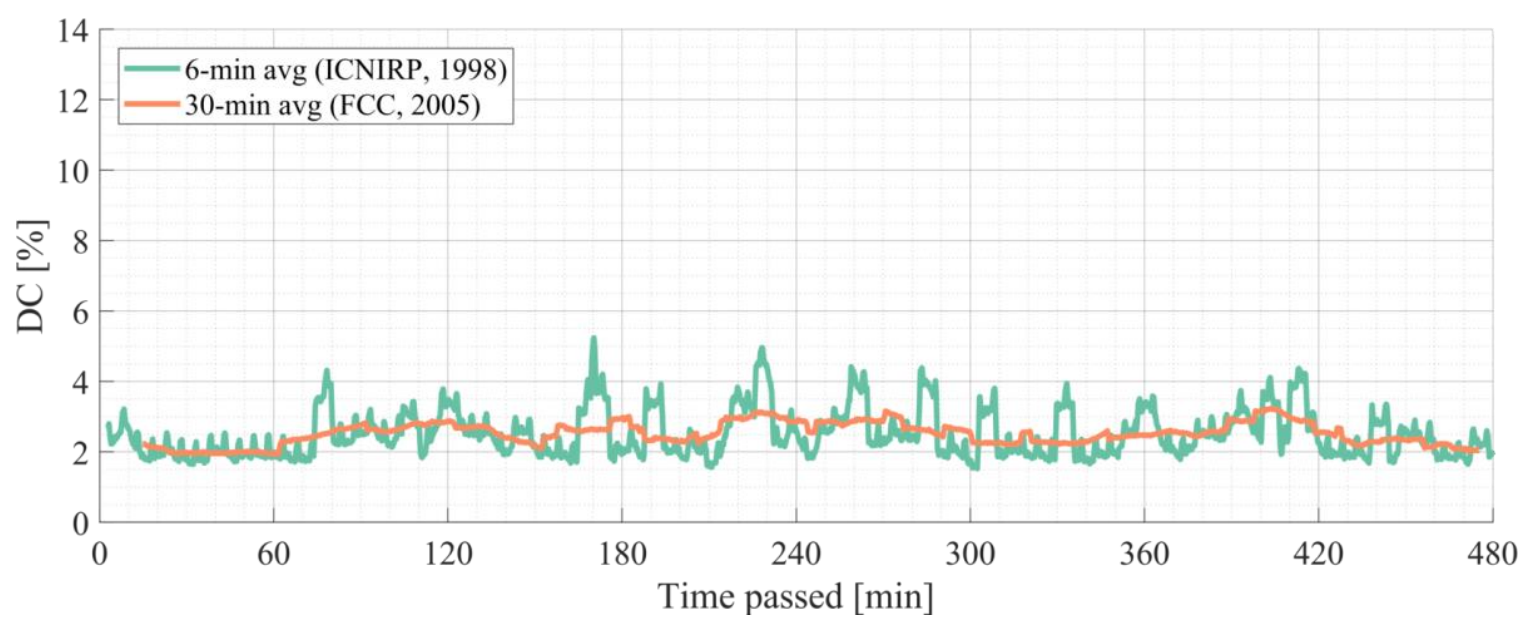

(a) MS \#2 (24 meters)

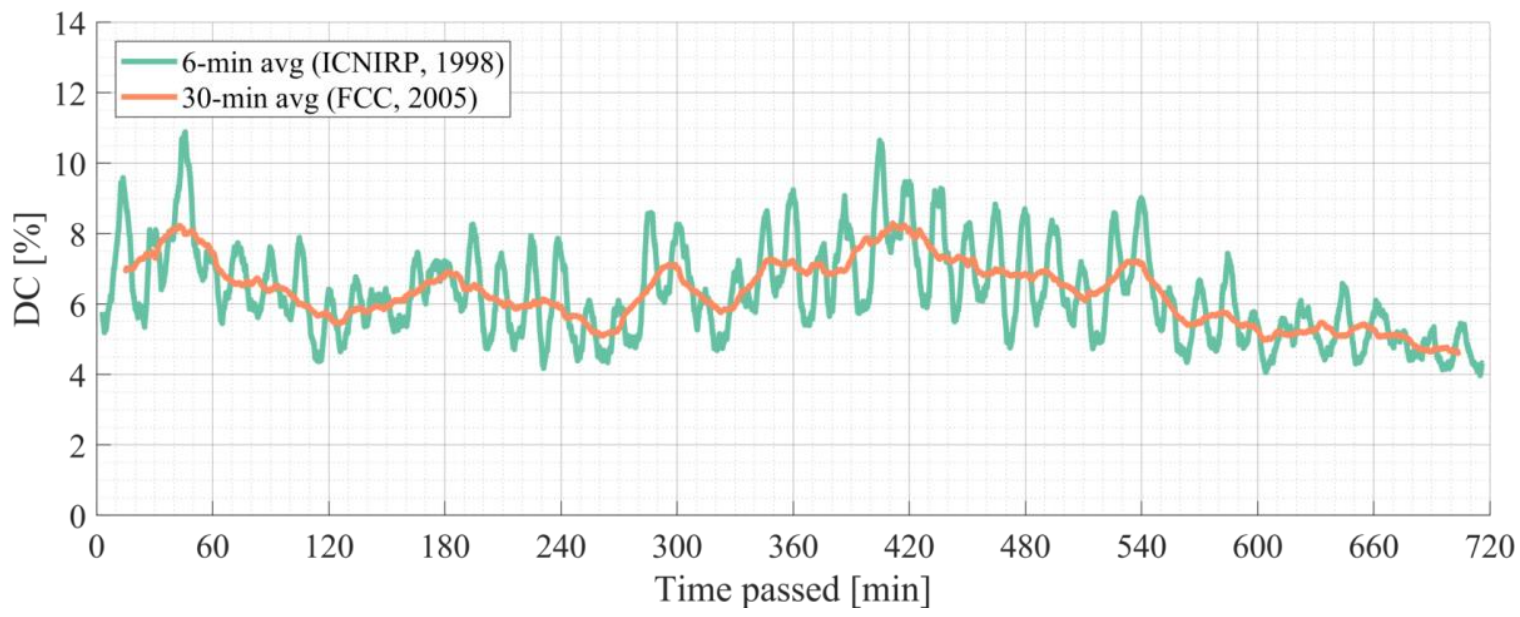

(b) IS \#4 (20 meters)

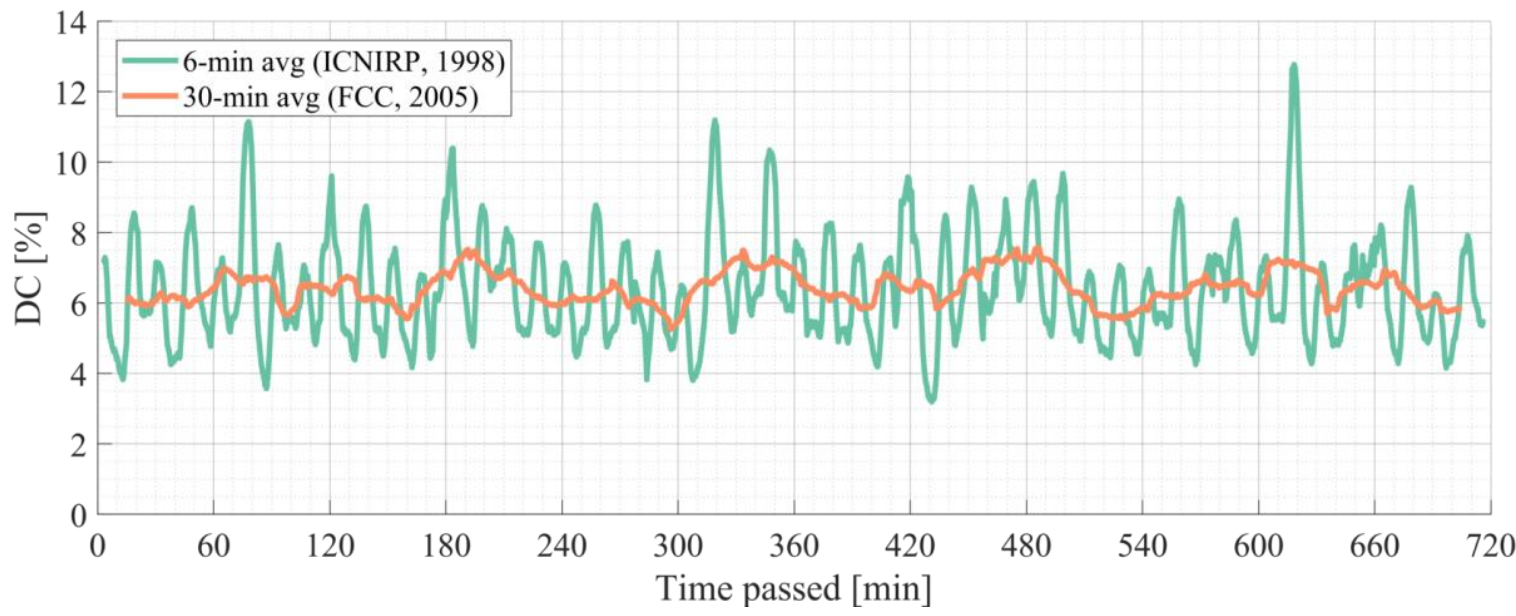

(c) IS \#5 (81 meters)

Figure 8: Temporal measurements of AMI meter banks at (a) MS \#2, (b) IS \#4, and (c) IS \#5.

Surprisingly, the inter-peak distance of the 6-min average DC was $5 \mathrm{~min}$ at both IS \#1 and IS \#2 (Figure 7), implying the TI was $5 \mathrm{~min}$ instead of the expected $15 \mathrm{~min}$. Moreover, these TI-induced peaks were accompanied by two to three times higher peaks at random (IS \#1, Figure 7a) or at periodic intervals (IS \#2, with an inter-peak distance 130 min, Figure 7b). This finding shows the need for performing in-situ temporal measurements of AMI as the theoretical DC may differ. 
Furthermore, the ten-fold difference in $\mathrm{DC}_{6-\text { min }}$ between the single meters (Figure 7 and Table 2) may be explained by their network configurations. The smart meter at IS \#1 was a stand-alone meter, directly and wirelessly connected to a dedicated access point within the AMI network and with few other AMI meters operating nearby, which results in fewer non-readout transmissions. On the other hand, the meter at IS \#2 operated in a crowded mesh network consisting of AMI meters throughout the neighborhood. Hence, the latter situation compared more closely with the meter shop measurements, where $\mathrm{DC}_{\text {avg }}$ for a single meter was $0.15 \%$ (with $\mathrm{TI}=5 \mathrm{~min}$ also) (Table 2 ).

At the other in-situ locations, distinct 15-min spaced peaks in $\mathrm{DC}_{6 \text {-min }}$ were observed, which were quite variable in peak values (Figure $8 \mathrm{~b}$ and c). In the meter shop, on the other hand, where TI $=5 \mathrm{~min}$, peaks in $\mathrm{DC}_{6-\mathrm{min}}$ were indeed observed at 5-min intervals for both MS \#2 (Figure 8a) and MS \#3 (not shown). DCs of the latter were roughly twice as high as for the former (Table 2), which also contained half the amount of smart meters.

The DC of the 24-meter bank in the meter shop was similar to the DC of the in-situ 46-meter bank $\left(\mathrm{DC}_{6 \text {-min,avg }} \approx 2.5 \%\right.$; Table 2), while the DCs of the 48-meter bank and the in-situ 81 meter bank were roughly twice as high $\left(\mathrm{DC}_{6-\text { min,avg }} \approx 5-6 \%\right.$; Table 2$)$. Besides the faster TI in the meter shop, the difference in number of meters resulting in similar DCs may be explained by the network architecture in which the meters were operating: the meter shop configurations had an unknown number of AMI meters being tested independently (and at a sufficient distance) from the measurements. One would indeed expect more inter-meter communications in more crowded networks (which was also the case at MS \#2). This may also (partly) explain the similarity of the DC of the in-situ 20-meter bank with the latter pair: in the 33-story apartment building (IS \#4), multiple meter banks were installed above and below the 5th floor. On top of that, its metal cabinet enclosure may have resulted in a more frequent data loss, a higher number of re-transmissions, and thus a higher duty cycle. However, as expected, the 81-meter configuration resulted both in the highest average and maximum 6-min average duty cycle in with $\mathrm{DC}_{6-\min , \max }=12.77 \%$ (Table 2). For comparison, a DC of just $0.29 \%$ was found by Tell et al. (2013) for a 112-meter bank (different vendor, but a similar RF mesh network and also operating within the ISM $915 \mathrm{MHz}$ band) using a 3-min zero-span measurement.

Alternatively, a DC may also be estimated using logs of transmitted data packets (Tell et al., 2012; 2013), unlike the described method of directly measuring it. This way, Tell et al. $(2012,2013)$ estimated maximum DCs of single meters (from different vendors in a similar RF mesh network and operating within the ISM $915 \mathrm{MHz}$ band) of 0.08\%, 4.74\%, and 13.9\%, using different data acquisition techniques, and median DCs ranging between $0.01 \%$ and $0.06 \%$ (although no TI was reported). Moreover, for electricity smart meters using ZigBee (IEEE, 2011) and operating at $2.4 \mathrm{GHz}$, Peyman et al. (2017) estimated DCs (also based on data packets) between $0.09 \%$ and $1.06 \%$. 


\subsection{Exposure assessment}

Lastly, to compare the study's results to the ICNIRP and FCC/IEEE maximum permissible exposure guidelines (FCC, 1997; ICNIRP, 1998; IEEE, 2005) using the exposure ratio $R$ defined in Eq. (3), the maximum time-averaged exposure levels were calculated with Eq. (2) from the worst-case (assuming a DC of $100 \%)$ electric-field strengths $\left(E_{\max }\right)$ and the maximum $x$-min duty cycles $\left(\mathrm{DC}_{\mathrm{x}-\min \text {,max }}\right.$ with $x=6$ for ICNIRP (1998) and $x=30$ for FCC (1997) and IEEE (2005)) obtained per meter configuration. The results are listed in Table 2: all time-averaged exposure levels at $0.3 \mathrm{~m}$ were well below the ICNIRP and FCC/IEEE guidelines.

For single meters, maximum ICNIRP exposure ratios $\left(R_{I C N I R P, \max }\right)$ of $0.007 \%$ to $0.06 \%$ were found (Table 2). As the field levels at all single-meter locations were similar (Figure 5), the ten-fold higher maximum was due to the $\mathrm{DC}_{6-\min , \max }$ of $0.63 \%$ obtained at IS \#2. For meter banks (with 24 to 81 smart meters), $R_{I C N I R P, \max }$ ranged between $1.58 \%$ and $9.43 \%$, with the greatest values due to higher field levels and DCs. Averaging the DC over $30 \mathrm{~min}$ instead of $6 \mathrm{~min}$ allows comparison with the FCC/IEEE guidelines (FCC, 1997; IEEE, 2005) (Table 2): FCC/IEEE exposure ratios ( $R_{F C C / I E E E}$ ) were between $0.001 \%$ (single $\mathrm{AMI}$ meter, with a $\mathrm{DC}_{30-\min \text {,max }}$ of $0.02 \%$ ) and $5.39 \%$ (20-meter bank, with a $\mathrm{DC}_{30-\min \text { max }}$ of $8.30 \%)$.

\subsubsection{Comparison to other residential RF sources}

To put the RF-EMF exposure to smart meters and smart meter banks in perspective, Figure 9 compares their (ICNIRP) exposure ratios to those of a wide range of other household sources of RF-EMF, as measured in a previous study (Aerts et al., 2019). At a distance of $0.5 \mathrm{~m}$, the exposure to an Aclara I$210+\mathrm{cn}$ smart meter (interpolated to this distance via the model of Eq. (1)) is comparable with the exposure to wireless access points and cordless phones $\left(R_{I C N} \sim 0.001\right.$ to $0.01 \%$, Figure 9 ) and lower than the exposure to Belgian electricity meters' communications modules, which use GPRS $(R \sim 0.1 \%$, Figure 9). Furthermore, while the $R_{I C N I R P}$ comparison of meter banks to household sources can seem relatively high, they represent a worst-case scenario. These comparisons do not consider actual use or proximity of the source to the user, a strong determinant of exposure. Smart meter(s) (banks) are typically installed at locations away from people (for instance in this study: in the basement, attached to an exterior wall, and in a metal cabinet in a hallway), which has a large influence on the potential exposures. Even given the worst-case scenario nature of these measurements, the $R_{I C N I R P}$ of meter banks still are well below ICNIRP's maximum permissible exposure limit 


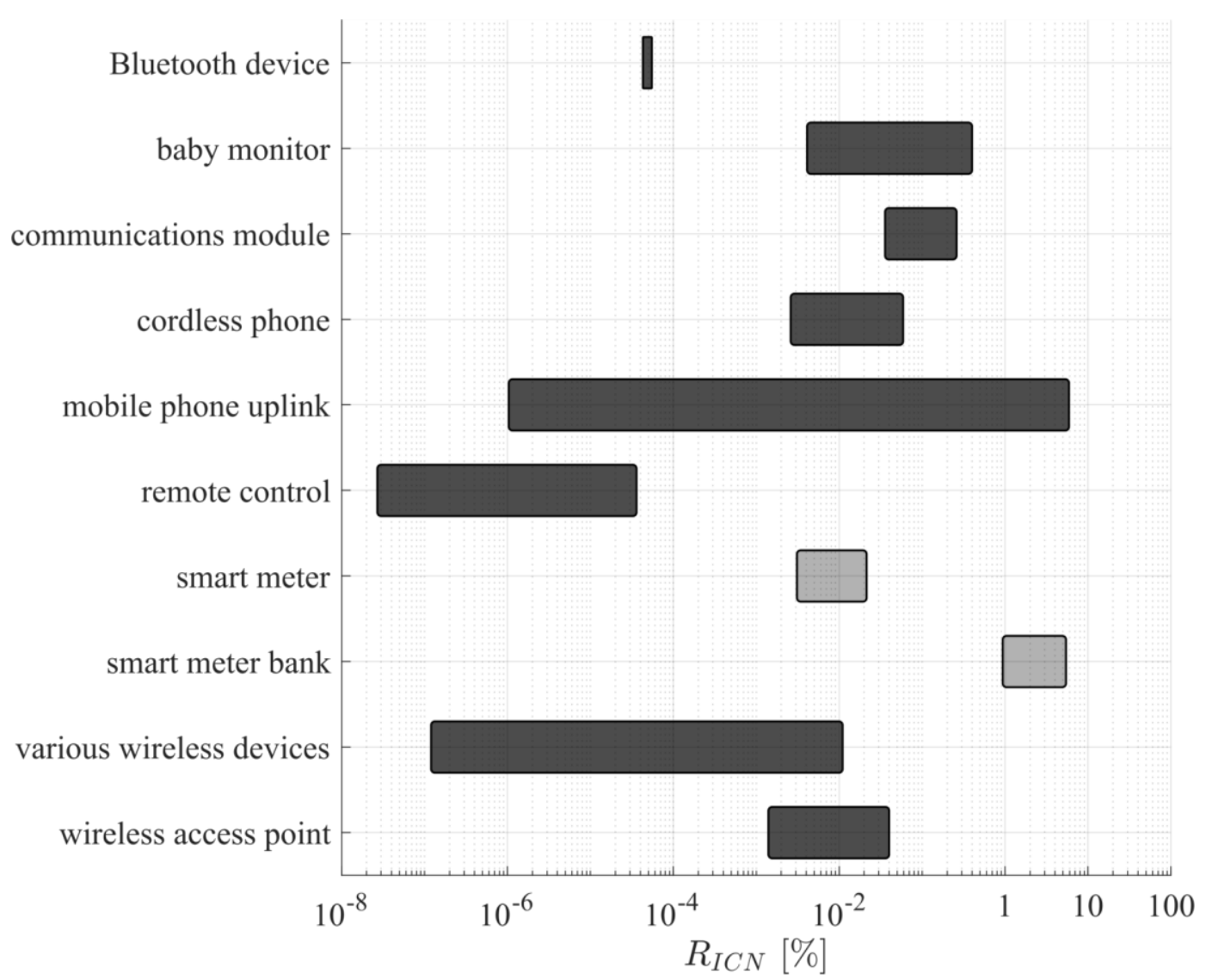

Figure 9: Overview of the range of exposure ratios $R_{I C N}$ at $50 \mathrm{~cm}$ from a variety of household sources of RF-EMF as presented in (Aerts et al., 2019). The ranges found in this study for smart meters and smart meter banks are indicated in light grey. (The category "various wireless devices" includes e.g. thermostats, weather stations, and motion sensors.)

\subsubsection{Comparison to smart meters using ZigBee at $2.4 \mathrm{GHz}$}

Furthermore, some types of smart meters (also) operate in the ISM $2.4 \mathrm{GHz}$ band, using ZigBee technology with frequencies between $2405 \mathrm{MHz}$ and $2480 \mathrm{MHz}$ (IEEE, 2011). This type of communication is prevalent in 'home area networks' or HANs, in contrast to the smart meters of this study (and of the studies by Foster and Tell (2013) and Tell et al. (2012; 2013)) that operate in mesh 'neighborhood area networks' or NANs. Peyman et al. (2017) investigated a number of smart meters that use ZigBee technology at $2.4 \mathrm{GHz}$ (including electricity meters, communications hubs, in-home displays, and gas meters) under laboratory conditions and reported maximum power densities at $0.5 \mathrm{~m}$ between $0.2 \mathrm{~mW} / \mathrm{m}^{2}$ and $15 \mathrm{~mW} / \mathrm{m}^{2}$ (and a potential outlier of $91 \mathrm{~mW} / \mathrm{m}^{2}$ ). In their follow-up study, Calderon et al. (2019) further assessed this type of smart meters (using ZigBee at $2.4 \mathrm{GHz}$ ) in 20 homes across England. They found peak power densities of approximately $0.1 \mathrm{~mW} / \mathrm{m}^{2}$ to $50 \mathrm{~mW} / \mathrm{m}^{2}$ (with geometric mean $2.02 \mathrm{~mW} / \mathrm{m}^{2}$ ) at $0.5 \mathrm{~m}$ for single smart meters and $12.1 \mathrm{~mW} / \mathrm{m}^{2}$ at $0.5 \mathrm{~m}$ for a meter bank of 16 devices, and 6-min duty cycles of respectively $0.01-1.19 \%$ and $5.2 \%$. When compared to the maximum power densities of $199 \mathrm{~mW} / \mathrm{m}^{2}$ (single smart meter) and $2243 \mathrm{~mW} / \mathrm{m}^{2}$ (meter bank) (interpolated values at $0.5 \mathrm{~m}$, using the model of Eq. (1)) and 6-min duty cycles of respectively $0.007-$ 
$0.63 \%$ and $1.53-12.77 \%$ (Table 2) measured in this study, it is clear that smart meters operating in HANs using ZigBee technology at $2.4 \mathrm{GHz}$ emit much less than devices operating in WANs, which is only logical as the former's range does not have to extend outside of the residence. However, it is important to note that even in the case of a HAN, a device (such as a communications hub (Calderon et al., 2019) or communications module (Aerts et al., 2019)) will be present that wirelessly communicates the meter readings to a WAN gateway (in a NAN) or directly to the utility, in which case it is also part of a 'wide area network' or WAN.

\subsection{Strengths and limitations}

In-situ assessment of the RF-EMF exposure to single AMI smart meters and multi-meter banks was performed in five diverse urban settings in New York City and Westchester County, New York. The exposure assessment consisted of measurements reflecting potential worst-case electric-field levels at various positions near the smart meter(s) and of the real duty cycle which were combined into the timeaveraged exposure levels, which were then compared to ICNIRP or FCC/IEEE maximum permissible exposure guidelines. To the authors' knowledge, this study was the first time that spatial and temporal exposure measurements of smart meters and meter banks were conducted using the spectrogram of a spectrum analyzer in zero-span mode instead of frequency mode.

The advantage of using the SA's zero-span mode in combination with the spectrogram function for the measurements of the worst-case electric-field strength lies in its ability to detect simultaneous emissions from multiple meters as higher received power levels (as measured over the entire 902-928 MHz band). As simultaneous emissions probably occur in different frequency channels, to avoid packet collisions and thus data loss, frequency mode measurements cannot reliably capture the total received power unless they are performed extremely fast (faster than was possible with the SA setup of this study). For comparison, Tell et al. (2013), who used frequency mode measurements and retained only the "single greatest channel value," reported peak field levels in front of a 112-meter bank that were "essentially no different than those in front of individual smart meters," which was not observed in this study (Figure 5). Instead of using estimates based on the log of transmitted data packages (Tell et al., 2012; 2013; Foster and Tell, 2013), the actual DC was calculated using long-term measurements of up to $12 \mathrm{~h}$. Furthermore, since in-situ measurements are usually constrained by time, alternative methods were explored to derive accurate DCs from the short-term spatial measurements (which were also done in zero-span mode). It was found that the DCs derived from the spatial measurements lasting 48 min differed relatively little from the long-term DCs. In general, 10-25\% higher $\mathrm{DC}_{6 \text {-min,max }}$ were obtained from the latter, while the largest difference was observed at IS \#2 (67\% higher), probably due to missing the periodic peaks in $\mathrm{DC}_{6-\min }$ of $\sim 0.6 \%$ when conducting short-term measurements (Figure $7 \mathrm{~b}$ ). However, in the meter shop, where spatial measurements lasted only 16 min due to the smaller TI, the difference in DC increased to 
up to $120 \%$. Hence, although a dedicated long-term measurement $(\sim 12 \mathrm{~h})$ remains the best option to assess the DC, the spatial short-term measurements offer a decent alternative in case of time constraints. Although smart meters operating only in the ISM $915 \mathrm{MHz}$ band (and using frequency-hopping spread spectrum) were assessed in this study, the presented measurement procedure may be applied to other smart meters or other non-continuous RF sources. However, to obtain accurate measurements for each of the three orthogonal electric-field components successively (using the zero-span method), a relatively short TI works best, i.e. up to $20 \mathrm{~min}$ for a one-hour spatial measurement. Alternatively, in case the TI is impracticably long, a single measurement at a known distance from the AMI system would be sufficient to calculate the exposure levels at other distances using the model of Eq. (1) and the parameters noted in Table 3.

\section{Conclusions}

Both spatial and temporal radiofrequency (RF) electromagnetic field (EMF) measurements were performed near single and aggregations ("banks") of advanced metering infrastructure (AMI) smart meters in a meter shop and in diverse urban settings at five locations. The assessed meters operated in the US unlicensed $915 \mathrm{MHz}$ band using frequency-hopping spread spectrum method. The measurements consisted of gauging the RF environment, evaluating the worst-case field levels around the AMI meter configuration (spatial assessment), and calculating the duty cycle of the configuration, i.e. the fraction of time the meter(s) actually transmitted (temporal assessment), after which the latter two measurements were combined to obtain time-averaged exposure levels.

Overall, maximum electric-field levels of 10-13 V/m were obtained for a single meter and 18-38 V/m for meter banks (with 20 to 81 meters), while 6-minute averaged duty cycles of $0.01 \%$ (one meter) up to $13 \%$ (81-meter bank divided into two opposite banks) were observed. For all scenarios, the measured exposure levels at $0.3 \mathrm{~m}$ and beyond were well below reference levels (or maximum permissible exposure limits) as issued by the International Commission on Non-Ionizing Radiation Protection (ICNIRP, 1998), the U.S. Federal Communications Commission (FCC, 1997), and the Institute of Electrical and Electronics Engineers (IEEE, 2005). The worst-case, time-averaged exposure level (at $0.3 \mathrm{~m}$ ) amounted to $9.43 \%$ of the ICNIRP and $5.39 \%$ of FCC/IEEE reference levels.

Furthermore, two well-fitted prediction models of the peak electric field strength as a function of distance were constructed. The single-meter model should be valid for all meters of the considered type, whereas for meter banks, at least one field measurement at a known distance may be needed prior to using the prediction model.

Finally, future work entails the evaluation of other AMI smart meters types (using e.g. 4G Narrowband (NB) IoT or ZigBee) to examine the general applicability of the presented measurement procedure. 


\section{References}

Aerts S, Verloock L, Van den Bossche M, Martens L, Vergara X, Joseph W. 2019. Emissions from smart meters and other residential radiofrequency sources. Health Phys. 116:776-788.

Calderon C, Addison D, Chopra N, Mann S, Maslanyj M, Peyman A. 2019. Exposure to Electromagnetic Fields From Smart Utility Meters in GB; Part III) On-Site Measurements in Homes. Bioelectromagnetics 440:434-440.

de Miguel-Bilbao S, Karpowicz J, Febles V, Hernández JA, Suárez S, Ramos V, Gryz K. 2017. Electromagnetic Exposure Hot-spots in a Healthcare Environment, Caused by Smart Metering to Control Public Utilities. 6th IEEE Int. Conf. E-Health Bioeng. - EHB 2017, 603-606. Sinaia, Romania. European Committee for Electrotechnical Standardisation (CENELEC). 2008. Basic standard for the in-situ measurement of electromagnetic field strength related to human exposure in the vicinity of base stations. Brussels, Belgium: TC 106x WG1 EN 50492.

Federal Communications Commission (FCC). 1997. Evaluating Compliance with FCC Guidelines for Human Exposure to Radiofrequency Electromagnetic Fields. OET Bulletin 65, edition 97-01.

Friis, HT. 1946. A Note on a Simple Transmission Formula. IRE Proc. 34(5): 254-256.

Foster KR, Tell RA. 2013. Radiofrequency energy exposure from the Trilliant smart meter. Health Phys. 105:177-86.

Girnara K, Zombolas H, Wood A. 2011. AMI meter electromagnetic field survey. EMC Technologies; Final Report Document Number M110736. Keilor Park, Australia.

Institute of Electrical and Electronics Engineers (IEEE). 2005. IEEE Std. C95.1-2005. IEEE Standard for Safety Levels with Respect to Human Exposure to Radio Frequency Electromagnetic Fields, $3 \mathrm{kHz}$ to $300 \mathrm{GHz}$. New York, NY, USA: IEEE Computer Society.

Institute of Electrical and Electronics Engineers (IEEE). 2011. IEEE Std 802.15.4. IEEE Standard for Local and metropolitan area networks- Part 15.4: Low-Rate Wireless Personal Area Networks (LRWPANs). New York, NY, USA: IEEE Computer Society.

International Commission on Non-Ionizing Radiation Protection (ICNIRP). 1998. Guidelines for limiting exposure to time-varying electric, magnetic, and electromagnetic fields (up to $300 \mathrm{GHz}$ ). Health Phys. 74:494-522.

Joseph W, Verloock L, Goeminne F, Vermeeren G, Martens L. 2012. Assessment of RF exposures from emerging wireless communication technologies in different environments. Health Phys. 102: 161-172. 
Peyman A, Addison D, Mee T, Goiceanu C, Maslanyj M, Mann S. 2017. Exposure to Electromagnetic Fields From Smart Utility Meters in GB ; Part I) Laboratory Measurements. Bioelectromagnetics 38:280-294.

Qureshi MRA, Alfadhl Y, Chen X, Peyman A, Maslanyj M, Mann S. 2018. Assessment of Exposure to Radio Frequency Electromagnetic Fields From Smart Utility Meters in GB; Part II) Numerical Assessment of Induced SAR Within the Human Body. Bioelectromagnetics 39:200-216.

Tell RA, Sias GG, Vasquez A, Sahl J, Turman JP, Kavet RI, Mezei G. 2012. Radiofrequency fields associated with the itron smart meter. Radiat Prot Dos 151:1-13.

Tell RA, Kavet R, Mezei G. 2013. Characterization of radiofrequency field emissions from smart meters. J. Expo. Sci. Environ. Epidemiol. 23:549-553.

Verloock L, Joseph W, Vermeeren G, Martens L. 2010. Procedure for assessment of general public exposure from WLAN in offices and in wireless sensor network testbed. Health Phys. 98(4):628-638. 